\title{
OLD RAUMA (FINLAND): LIVING AND RESEARCHING VERNACULAR ARCHITECTURE
}

\author{
M. Caruso ${ }^{1, *}$, L. García-Soriano ${ }^{1}$ \\ ${ }^{1}$ Universitat Politècnica de València, Valencia, Spain - maticaru@ gmail.com, ligarso@upv.es
}

Commission II - WG II/8

KEY WORDS: Nordic Vernacular Architecture, Old Rauma, Wooden Vernacular Architecture, Vernacular Heritage Studies, Heritage Researches, WHS analysis

\begin{abstract}
:
Old Rauma is a Finnish medieval town. It was founded in the 15th century and although it went through several modifications, it maintained significative features of medieval Nordic urbanism and vernacular architecture. Buildings mostly consist of logs-timber structures, even if there are also few cases of stone constructions; dwellings are usually simple volumes composed of a stone cellar, a first main floor and an attic, that is used for ventilation and secondary domestic activities. The wood is the most used material and slabs, floors, doors, windows, finishing and decorations are made of it. People still live in traditional dwellings or use them with other functions. Some significant changes were necessary to adapt the buildings to the modern lifestyle: although some of them were quite modifying, the upgrades are often operated by using traditional techniques, materials and by maintaining the most relevant architectural features. Thank to this habit, Old Rauma is one of the largest and most important examples of Nordic traditional architecture. This text will present the results of 2 months of direct field research, by explaining the work methodology, its results and some considerations about them. The analysis has been conducted during a traineeship at Tammela Centre (Rauma) and it has been carried out by visual surveys, bibliographical researches, active participation to seminars and activities, photographical cataloguing and through interviews with local professionals, experts and inhabitants.
\end{abstract}

\section{INTRODUCTION}

Old Rauma is an ancient medieval Finnish town approximately inhabited by 800 people and composed of around 600 traditional wooden dwellings (Jämsä, 2012). While some of them have conserved house function, others were changed into shops, bars, restaurants, banks and offices. Although lifestyle and habits evolved, the historical nucleus preserved most of its original architectural and urban features, making of Old Rauma a rare example of an ancient Nordic medieval town that is still inhabited and "active". Due to this situation, it was declared World Heritage Site by the UNESCO on 1991 (Raitio, Tammi, 2018). These circumstances make it a case worthy of being analysed, not only to understand the local culture, but especially for investigating how conservation is managed, for detecting the main problems and strengths and for finding out old town's actions in terms of preservation and valorisation. The knowledge thusly acquired could result extremely convenient since it can be used for the management of other World heritage sites; besides, it can also be employed for architectural studies. Due to these reasons, Old Rauma was the object of the following presented work of research, carried out by the author for her master's degree final dissertation.

\section{THE RESEARCH: STRUCTURE AND RESULTS}

The research, that was also a possibility to explore and verify investigation methodology on built heritage, started on December 2018. Its most relevant part took place in Rauma, between August and September 2019 and it ended on December 2019 , with the official final dissertation of the work. These moments also correspond with the 3 main phases of the research: the first one was focused on preliminary studies, mostly brought on by bibliographical analyses. The second period coincided with the 2 months field work conducted in the very Old Rauma. Finally, all the data collected were elaborated during the last phase, which also brought to the ultimate written form of the work.

\subsection{Phases of the work}

First phase was carried on between December 2018 and March 2019, through bibliographical and graphical previous studies especially based on some books from Rauma's museums, satellites photos and maps. This analysis built a basic understanding of Old Rauma's history, architecture and urbanism; besides, it allowed to draft preliminary drawings and hypothesis about the town shape, considering the features of streets, squares, blocks and parcels. After the collection of this material, a first index of the work was drafted, providing the paths to follow on next stages.

The second phase of the research took place in the very Old Rauma, with a stay of 2 months as researcher at the RaumArs artist residency and as apprentice at Tammela Renovation Centre, a special institution which is vital for the old town preservation ${ }^{1}$. This stage led to a massive data collection: during the stay, Old Rauma was analysed and studied through direct explorations conducted at different times of the day and in different situations. Besides, many of the vital mechanisms of this World heritage site were experienced by directly participating in some of the activities organized by Tammela and Rauma communities, that also allowed to dialog with local experts. Explorations to the Satakunta's region ${ }^{2}$ and Rauma's surroundings were carried on by visiting Sammallahdenmäki World heritage site, the rural village of Irjianne and Toivo ${ }^{3}$; trough these visits the perspective on Rauma territory was

\footnotetext{
* Corresponding author

1 Further information about Tammela Centre can be found in section 2.3.4 of this text.

2 Satakunta is the Finnish region where Rauma is located.

3 Toivo is another Renovation Centre, similar to Tammela and located in Pori.
} 
widened and the analysis was implemented with a more complete view on local and regional traditions and habits. Furthermore, the contact with rural traditional architecture gave a more exhaustive understanding of materials, constructive techniques and composition. Although the work was focused on Old Rauma, these analyses were convenient to investigate the deep bound that connects local traditional architecture to life, needing and tradition.

The final phase lasted 3 months and it was conducted between October and December 2019. This part of the study was mainly aimed to analyse, complement and finalize the collected material and to produce the written final form of the work. During this stage several diagrams and text were realized, especially in virtual forms.

\subsection{Methodology and work structure}

Throughout the research course, four macro topics were investigated:

- the history of Old Rauma;

- its urban and architectural characterization;

- the analysis of the conservation state;

- the study of strategies of preservation and valorisation.

These aspects were analysed by following the previous order, that was established considering the knowledge propaedeutic: history was necessary to understand the evolution of urbanism and architecture and their characterization was, in turn, the base for setting up the final analyses.

The first focus was aimed to outline the historical and evolutive processes of Old Rauma, in order to detect the most important changes and features both in a cultural and urban meaning. It led to deepen the knowledge about the town's origins, evolution and development. For this this purpose, several local texts were studied and experts were interviewed. Through these operations, a chronologic path of the medieval settlement was reconstructed and it was later graphically summarised with diagrams, also based on historical maps and drawings. This process brought to the detection and comprehension of the most significant modifies, which later led to the development of the following topics.

After the preliminary studies, the focus moved on to urbanism and architecture, exclusively considering the vernacular typologies. During this phase, the previously collected historical data were crossed with present maps, plans, drawings and satellites photos. This process allowed to complete evolutional picture of the town and its dwellings, and to properly analyse blocks, parcels and houses features.

Concurrently with this operation, town and architecture were studied through external and internal visits to the buildings, brought on by travelling around Old Rauma. The measurement method was empirical and not metrically rigorous, since the main aim of the study was to display this World heritage site's structure, urbanism, architecture, culture and conservation. The permanence in the town was not long enough to permit accurate measurement operations, that would have taken time away from other studies and made impossible to investigate and present different topics.

To display the data collected many of diagrams were realised, especially 2D and 3D images such as schemes, sections, elevations, plans and axonometries that helped to represent the most important features. The analysis was firstly conducted through handmade draft drawings that were sketched during observation sessions to fix ideas and preliminary hypothesis. Sketches and diagrams were later complemented with photographs, maps and other kind of material and finally turned into virtual 2D drawings. Most of 2D main drawings were produced during the sojourn in Rauma and verified with the support of architectural manuals and discussed with experts.

An important amount of architectural and constructive data has been collected during the stay at Tammela and the visit to Toivo, thank to the possibility of directly observe the buildings structure. In there, architectonical components were studied not only through the archaeological windows, which are present in both centres, but also by the direct the exploration of the attics and cellars of Tammela. The accessibility of Tammela led to take the building as a reference for the virtual representation of Nordic traditional wooden house (Figure 1).

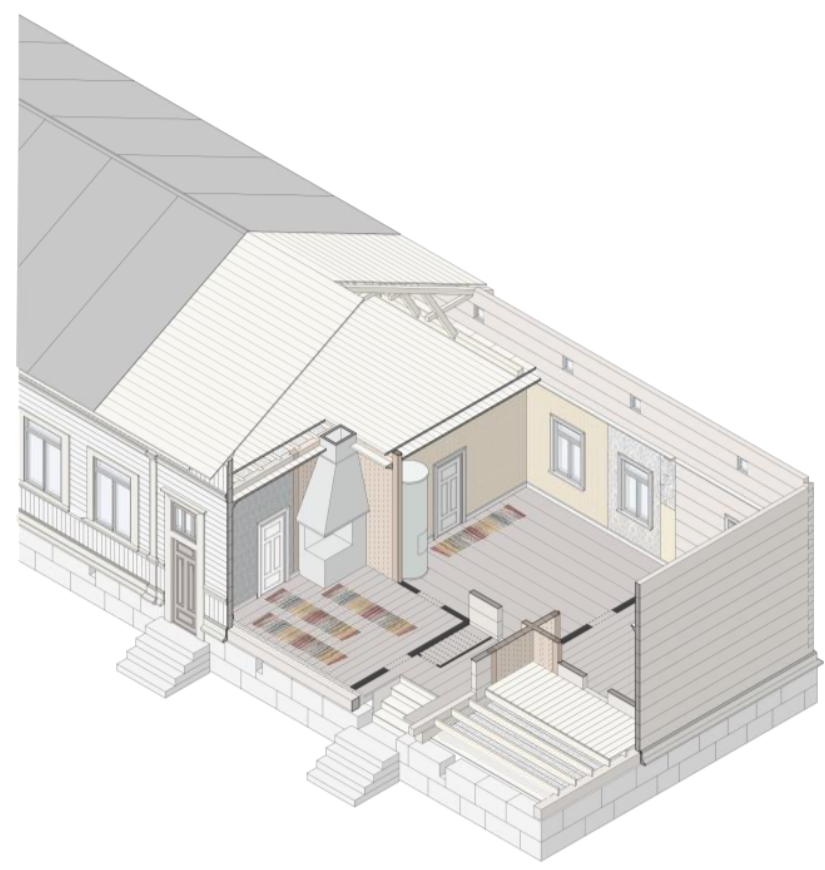

Figure 1. Axonometric section of Tammela's early XX configuration (digital drawing by the author, 2019).

Once the 2Ds were ready and verified, 3D virtual modelling was started (Figure 2). The virtual representation was drafted during the stay, in order to check it with local experts. The final form has mostly been carried out after the second phase, during November and December. The data where converted into 2D CAD drawings that were later used as base in the $3 \mathrm{D}$ modelling process.

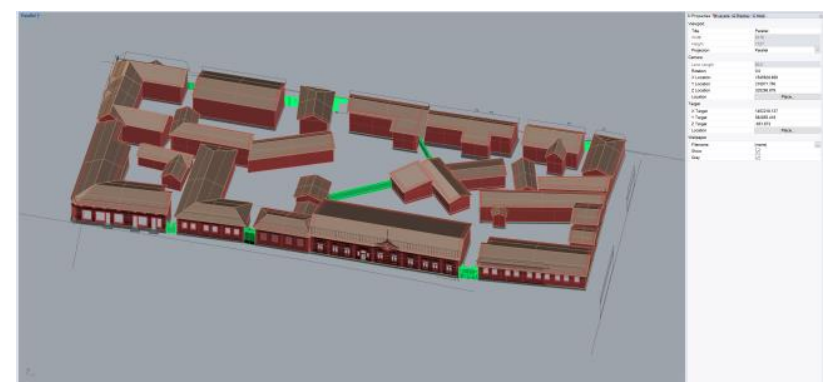

Figure 2. Virtual 3D modelling of Mairela House's block. 
The situation outlined by the researches on history, urbanism and architecture allowed the study to progress to the evaluation of the state of conservation. The analysis was conducted through direct observation: all the detected phenomena were firstly reported into a daily journal and described with a small text and a photo. The data collected were periodically verified by bibliography, further observations and trough the dialog with inhabitants and local professionals. The hypotheses were confirmed or corrected by them and sometimes new problems, which had not been detected already, were lined up.

Once the data were confirmed and deepened, they were organized into specific sheets, that classify the phenomena as structural or material. Every box is also filled with a photo or a diagram of the problem and contains its name, the part it is affecting, a short description, its grade of diffusion and its source. In sheets, hypotheses of the damage cause are provided as well, in order to enhance the understanding of the process and its mechanisms of deterioration (Figure 3).

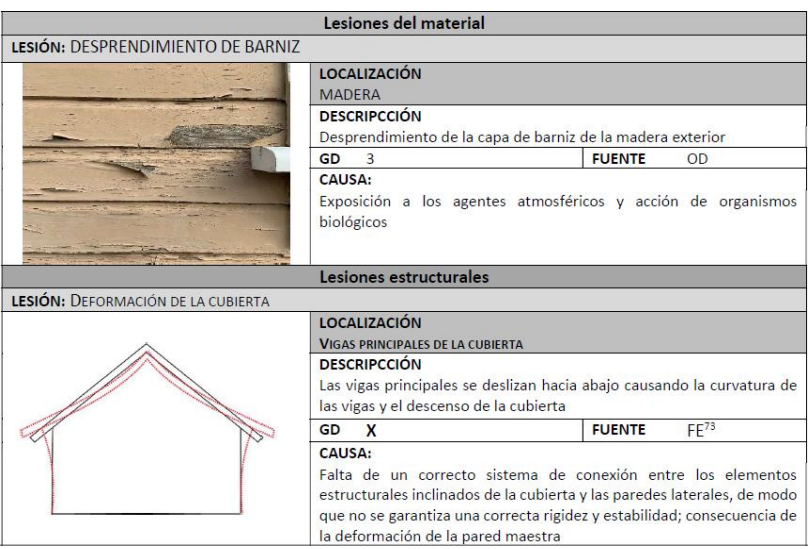

Figure 3. Two of the registered phenomena from the material and structural categories: the painting decay and roof deformation.

The evaluation scale for the grade of diffusion was divided into 3 levels, depending on the frequency of the phenomenon observation during the analysis. For not directly verified phenomena, the field is completed with an " $x$ ".

The source indicates the data obtention method, that could be bibliographic research, direct observation or dialog with experts. The classification is based on an empirical scale, since the temporal limits of the stay made impossible to deepen the analysis; yet, the diagram structure is suitable and employable for more detailed investigations.

The analysis of the conservation state was later extended to the territory, considering both Old Rauma's protected perimeter and its buffer zone. These areas were analysed through the crossing of historical-evolutive data with the information collected by the researcher and the aspects pointed out by locals and professionals. Texts and photographs were used to visual describe the phenomena and to display this phase of the study.

The analysis and verification of architectural state of conservation was mainly carried out during the stay in Rauma; the sheets were preliminary settled up in this moment, and they were later organized and modified into their final form during the last phase of the work. The territorial analysis started in the World heritage site through direct observation and dialog; during the final phase the research was also complemented with bibliographical information, that implemented the comprehension of the topic and pointed out some problems which were not detectable throughout the stay.

The conservation analysis outlined some of the criticalities and strengths of Old Rauma, that where finally investigated and presented in the last part of the work, the analysis of interventions, valorisation and diffusion strategies carried on in Rauma.

The interventions, meant as the actions carried out on dwellings by the very same users, were analysed together with the state of conservation, using a similar methodology. Another journal was employed to write down the actions observed, that were later verified through the same process and finally recollected into another sheets. In this case, interventions sheets are divided into 4 categories: new construction, ordinary maintenance or minor interventions, structural interventions and upgrade to modern standards. Every intervention is described by a photograph or a scheme, its name, the part it affects, a short description, its grade of diffusion and the source of detection. Besides, it was added another field, the grade of compatibility, that express the intervention suitability with the traditional system.

This part of the research was also aimed to understand the legal structure of management, that has been partially lined up during the stay through the dialog with experts. The information collected have been complemented during the last phase of the research through web and bibliographical materials that made possible to improve the understanding and to recognize some legal and managing aspects not detectable during the stay.

Last part of the study has been focused on diffusion and valorisation strategies, which were analysed through observation, through the direct participation in some of the cultural initiatives organized in Old Rauma and by dialoguing with locals.

The different detected events were later studied and analysed in order to understand their impact on society and heritage.

\subsection{Results}

The analyses carried out during the research were aimed to pursue different goals. First of them, the acknowledgment of Old Rauma's history, culture, urbanism and architecture. Since the town constitutes a relevant reference of traditional Scandinavian wooden architecture, those aspects are extremely important to understand this kind of heritage. Furthermore, they are vital for explaining and comprehend important mechanisms of its evolution and preservation processes. The study of conservation and intervention strategies has been carried out in order to detect the most jeopardizing criticises and to line up the strengths that should be protected and implemented. This kind of knowledge can lead to the formulation of a correct conservation interventions plan for the same Old Rauma. It also allowed to investigate the good practises detected in there, which can be exported and adapted to similar contexts.

Finally, a part of the research was especially dedicated to the production of virtual representations meant as key tool for diffusion and data archive, responding to 3D past project Living and Virtual Visiting World Heritage sites criteria. 
The global results of the work were also useful to understand the general complexity of dealing with the management of a World Heritage Site.

2.3.1 The historical analysis showed that the whole protected Old Rauma's area conserved its historical features, mostly preserving the ancient shape: on its origin, the settlement established around the Canal and Holy Trinity church and it was west-east oriented, with a longitudinal main street (which approximately corresponds with the actual Market Street) and composed by some patio blocks. The town grew and expanded toward the outside until the 17th century, when borders were fixed by fences (Salo, Sundelin, 2015): the perimeter established in that moment approximately corresponds to the actual protected area. Furthermore, during that time the King Street was created, and the centre of the town moved toward the north-western side, after the fire of the Holy Trinity church in 1640 (Koivula et al., 1992).

During the centuries many of different attempts were formulated to modify the topography. Their aim was mainly to reduce fire hazards and to satisfy latest city planning rules, which were thought for catching up with hygienic standards and design trends; although various plans and proposals were formulated, none of them was completely carried out, due to various problems and circumstances. Thusly, old limits did not change and architectural form was mostly maintained.

Old Rauma went through some relevant evolutions, like the New Classical and the Jugendstil restyles, that changed the town aspect during the 19th and 20th centuries (Koivula et al., 1992). These episodes followed the traditional architecture features by mostly maintaining its materials, sizes, techniques and composition, so they merged quite harmoniously with the existing constructions.

The most modifying changes were carried out during the 20th century, when several reforms were planned and, in some cases, also executed (Koivula et al., 1992; Salo, Sudelin, 2015). One of the most relevant is the conversion of many of dwellings into shops, that especially affected the core part of the town. A large number of changes resulted from these modifications, especially regarding composition and internal distribution: since shops needed to display their products, bigger windows were built. The previous façades morphology was changed while big portions of the wall were removed. Despite this occurrence, decorations, new doors and windows were built by following the tradition, so they can be classified as quite compatible with the rest of the old town (Raitio, Tammi, 2018). Furthermore, most of the shops and restaurants still exist nowadays and some of them are traditional local businesses which can be considered a part of the heritage as well.

During the 20th century, the World heritage site has been jeopardized by massive architectural transformations, through the building of new modern constructions not compatible at all with the ancient town. This trend started on the first decades of this period, with the construction of buildings like the Hotel in Kalatori. During the following years, it multiplied through new edifications, although it never really brought to the complete disfiguration of Old Rauma: in fact, many of the new buildings remained isolated episodes or they were realized in most marginal parts of the town. Besides, the latest new constructions, that have presumable been built during the last 30 years, appear more accorded to the traditional architecture, attempting to follow its size and composition (Figure 4).
Despite of those major problems, Old Rauma ancient topography and traditional architecture are still evident.

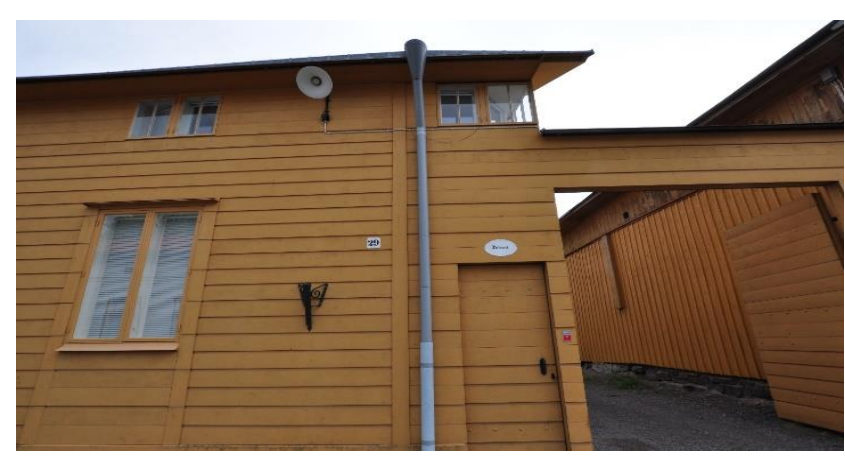

Figure 4. Modern house in Old Rauma (photograph by the author, 2019).

2.3.2 The architectonical and urban analyses highlighted that many of the blocks and of the old dwellings have been conserved, even though they went through heavily modifies.

Blocks have mostly irregular rectangular shapes, whose perimeter is usually delimited by the linear volumes of the main buildings. The access to the internal yard could be open or marked by a gate, while sometimes fences are used to delimitate the edge. Storage or small secondary constructions are usually located inside the patios, often used, nowadays, as gardens (Raitio, Tammi, 2018) (Figure 5).

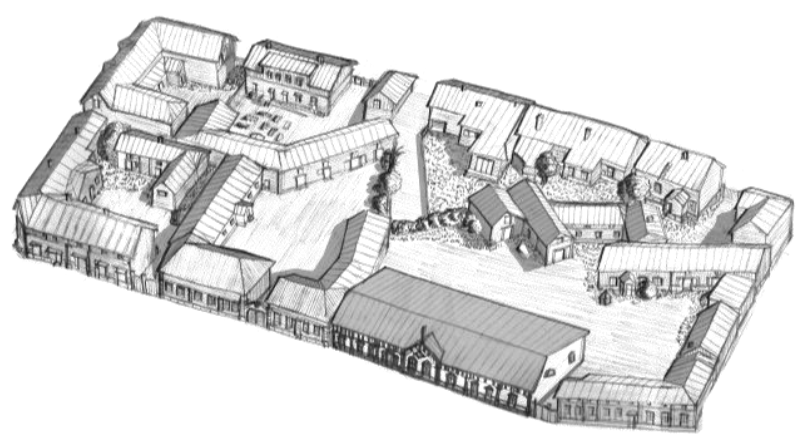

Figure 5. Sketch of a block (drawing by the author, 2019).

The traditional dwelling is usually a simple building composed of one floor, the ceiling and the attic. The only space used as living one is the main floor, while attics and cellars are employed for ventilation and secondary activities.

The base is composed by stone walls, that constitute the building foundations by growing thicker into the ground. The walls top, that lifts up from the terrain, forms the cellar volume which is also the base where the foundation beam of the upper parts rests. This beam also sustains the slab, a sandwich system whose structure is made of a monodirectional wrapping of wooden beams. A layer of wooden boards closes both the superior and inferior side of the slab and in its core sawing and fine pebbles are inserted for providing weight and insulation. The floor finishing usually consists in the same painted wooden boards or, more recently, in linoleum (Figure 6).

The wall structure is a wooden system made of piled logs. The exterior ones lay on the beams supported by the cellar structure and they are usually jointed in the corners; the same structural system is employed of interior walls, but their foundation beam 
usually rests on isolated piles of stones disposed in the cellar. interior local manufactured wallpaper is used (Figure 7). Exteriorly, houses are coated with wooden boards while in the

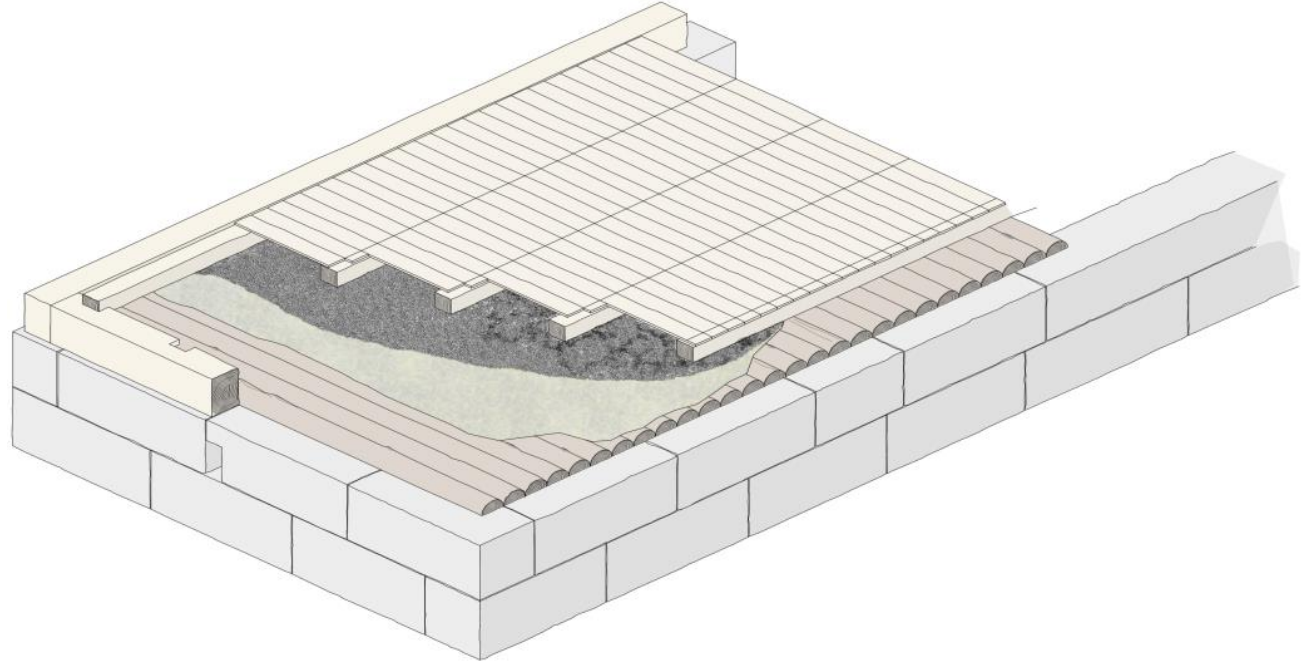

Figure 6. One of the most diffused wooden slab systems: in this case half logs are used as inferior closing surface (digital drawing by the author, 2019).

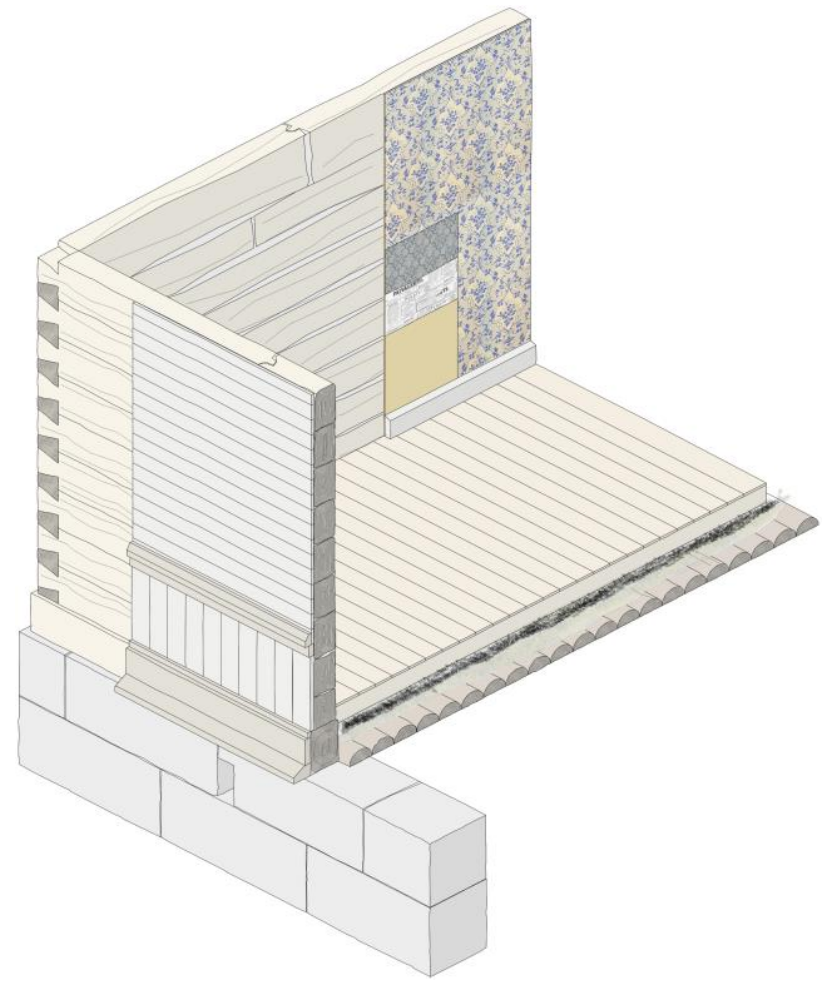

Figure 7. Logs walls system. In the scheme it is also possible to see the slab supported by the foundation beam of walls (digital drawing by the author, 2019).

The roof usually consists of a structure of 2 or 4 pitches, made of a similar-truss system (Figure 8). It is formed of 2 sloped main beams supported by a horizontal and an oblique element, respectively fixed to the exterior walls and to the $1^{\text {st }}$ floor slab. This system is closed by some wooden boards which often corresponded, in the past, with the final cover layer. Nowadays the most employed coat are metal foils, whose use diffused at the end of the 19 th century.

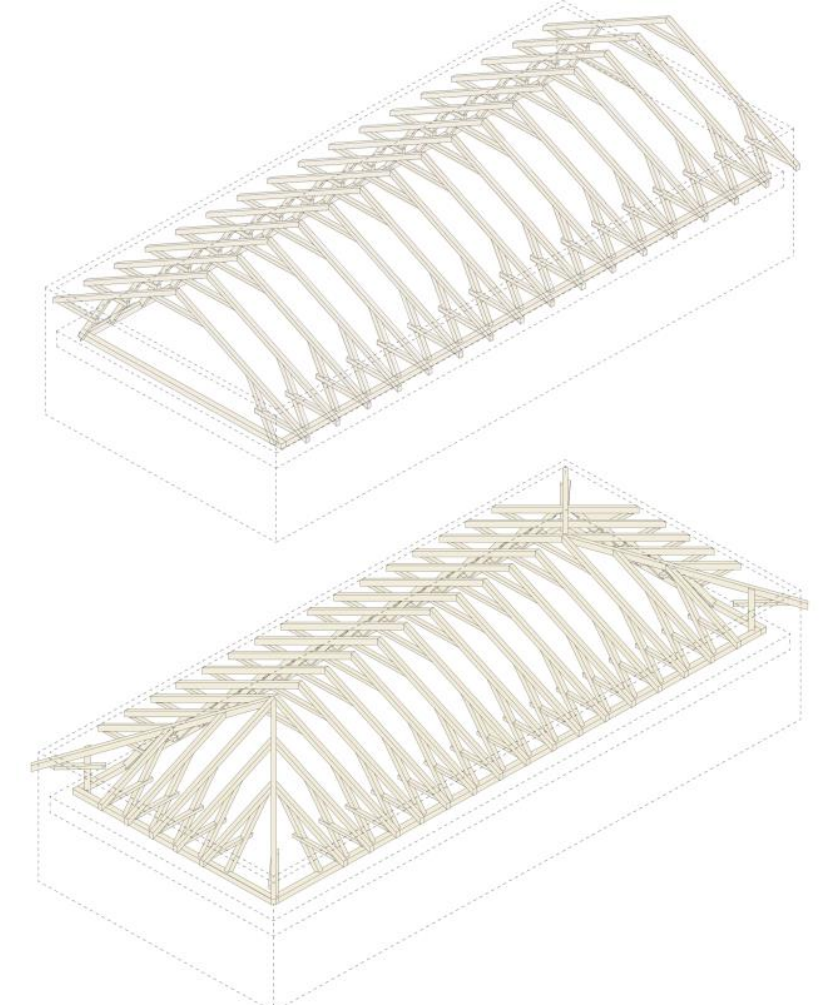

Figure 8. In the upper part, 2 pitches roof structure, in the lower part, 4 pitches roof structure (digital drawing by the author, 2019).

The residential tradition typology was quite flexible and singular unities within buildings gradually merged to form bigger houses, composed by those previous nuclei (Figure 9). Most of the residencies that still exist in the World heritage site are single-family houses whose rooms once formed singular dwellings. This kind of adaptation responds to the actual residential lifestyle and needing. 


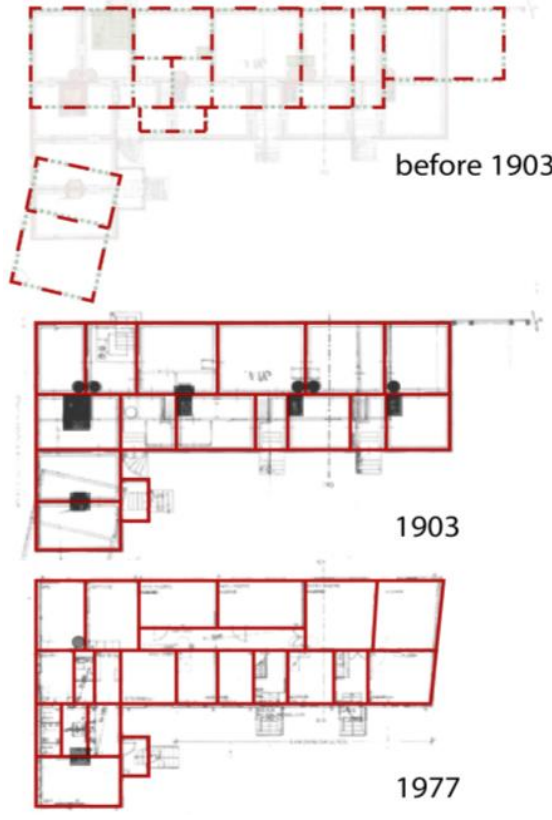

Figure 9. Tammela's evolution process: the original building was probably composed of single room-houses for different

families. During the1903 modifications these units were probably turned into 2 rooms-houses, while the music school configuration shows smaller rooms, all parts of the same school (schematized version by the author of some blueprints from the Centre's archive, 2019).

2.3.3 State of Conservation: during this process, materials and constructive techniques have been mostly preserved, even though it is necessary to remark that also newer elements and systems were introduced (Raitio, Tammi, 2018), such as metallic parts, concrete or more modern insulation fibres. Despite this new trend, the use of traditional constructive culture and materials is still quite diffuse, although in some cases incompatible materials and heavy modifications have been detected. Furthermore, the study of Rauma surroundings pointed out that tradition is still present in some single-family and isolated houses, that maintained conventional materials and composition while using more modern systems (Figure 10).

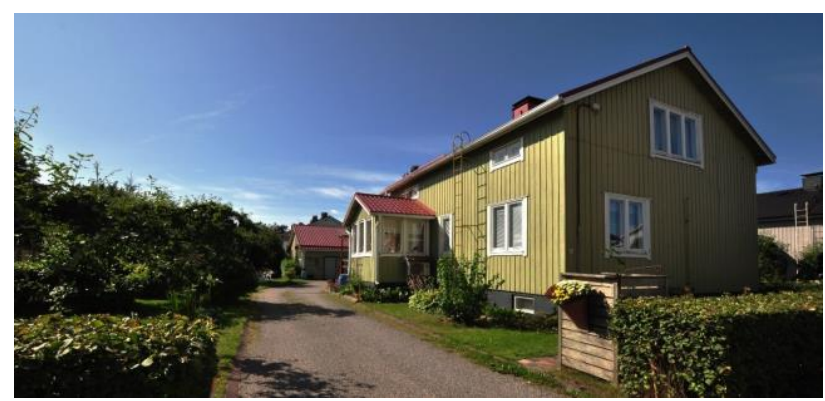

Figure 10. A modern house from the suburbs (photograph by the author, 2019).

The research on Old Rauma's state of conservation revealed that the town preservation is quite satisfactory. Despite of this, there are some serious struggles and processes that necessarily need to be controlled. Some of them have currently slowed down but it is crucial to completely stop them to guarantee the preservation of the World heritage site.
One of the most relevant phenomena is the construction of completely out of scale new architecture, often not related at all with traditional one (Dumitrescu, 2016). Its presence, both in the protected area and the buffer zone, can severely affect Old Rauma by gradually destroying and deleting the traditional architecture. It can also lead to the disconnection of the ancient area with the historical territory, especially when edifications are realized in the buffer zone.

Other worrying modification processes were detected inside the houses and in their private spaces. These changes, which often heavily affects the traditional building, can be extremely dangerous since it is difficult to detect and control them, due to the limited accessibility of the parts they are affecting. In fact, many of the internal yards and dwellings have been modified by changes often carried out using incompatibles techniques and materials (Raitio, Tammi, 2018). In some cases, completely incompatible elements were added or realized ${ }^{4}$ for upgrading the building to modern "aesthetical standards". Concurrently with this process, crucial architectonical and functional elements were sacrificed, such as protective layers, ventilation spaces, etc., often causing serious damages to the very same houses. This kind of trend results extremely difficult to be detected but it is necessary to strictly control and contain it since it could originate an "internal erosion". This phenomenon could later spread toward the outside, gradually but completely modifying the architecture forever. This way, not only traditional techniques and materials would go lost but it is also originated the risk to produce a low-quality architecture that would not last longer neither work better than the old traditional one.

Besides, another controversial trend spread around Old Rauma: stylish restoration and re-reconversion (Raitio, Tammi, 2018). These phenomena especially affect the commercial centre of Old Rauma, were most of the shops are located ${ }^{5}$. Due to its outstanding and representative architectural features, many of applications are registered from people who wish to live in this area, fact that would necessarily lead to the reconversion of shops and restaurants into residencies.

In some cases, reconversions have happened already, and they were carried out by restoring some elements that were dated back to the previous configuration without certain and historically accurate evidences. In other situations, some of the features proceeding from the Jugendstil period (like windows, decorations and similar) were removed and replaced with NeoClassical elements, which are considered more representative of Old Rauma style (Saarinen, 2013). Although modifications like these do not heavily damage the World Heritage Site, they still strongly affect the historical authenticity of it (Raitio, Tammi, 2018). If this process were to be expanded it could determine the old town's reconstruction based on modern tastes and beliefs. Another alarming phenomenon was pointed out by the research: the creation of large spaces deprived of local identity originated from the modern urbanization around the ancient town (Dumitrescu, 2016). These extended areas can gradually disconnect Old Rauma with its territory, completely deleting its historical bounds with nature and its elements (Figure 11).

\footnotetext{
such as the construction of big storages or new concrete pavements in the yards, the removal or addition of walls within the houses, the construction of new windows, the removal of wallpaper to display $\log$, etc.

5 the shop conversion was realised at the beginning of XX century, in a compatible way and it could be considered an historical phase with great value and so the buildings, that represent a valuable cultural layer.
} 


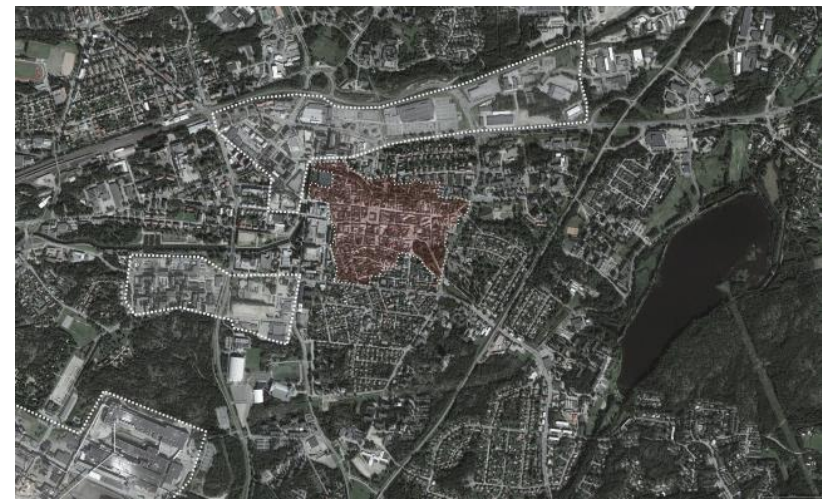

Figure 11. Rauma satellite photo: in red the protected area while the white shades are large industrial or commercial areas

(google Earth image, 05/08/2019)

Finally, the analysis also individuated new economic activities that are ready to be implanted in the territory and that could result extremely dangerous for the local traditional ones. Old Rauma economy, in fact, mostly consists of small activities, very fragile if compared with supermarket and franchising shops. Although they could appear "secondary" they are an important part and resource for the old town and it is necessary to preserve and to promote them.

2.3.4 Valorisation and laws: despite of this situation, Old Rauma's general conservation state could be considered quite satisfactory, especially when correlated with other European realities. Many of small maintenance works, such as wooden board substitution, windows and doors repairing, painting, etc., are daily carried out by the inhabitants during summer season.

This aspect should be considered crucial since users are the very main actors in conservation processes, given that their actions have big consequences on houses and their preservation (Dumitrescu, 2016). A quite diffused use of compatibles techniques ad material emerged from the analysis of intervention sheets. At the same time, also many criticises were detected, among which stands out the trend of upgrading using damaging systems and the switch to incompatible uses.

In order to prevent bad interventions, the local laws establish that projects for building works ${ }^{6}$ need to get the approbation of a nominated professional, who examine the level of compatibility with Old Rauma architectural features.

Furthermore, some care grants for the repairs and restoration in the World Heritage Site are managed by the Museovirasto ${ }^{7}$ : people who own a house in Old Rauma and want to do some interventions can apply for them; the projects that receive the subsidy are constantly followed and monitored during the building site by designated experts, who prevent bad practise to be carried out.

The grade of tutelage and the urbanistic tools depend on the local administration, that is responsible for the territorial and urban planning (Dumitrescu, 2016), that is not very restricted by national general advices or rules.

6 The authorization is required around the protected area, both for new constructions and interventions on already existing buildings.

The Museovirasto, or National Board of Antiquities, is the most relevant organization that deals with heritage in Finland (Dumitrescu, 2016)
Finally, Old Rauma can count on another important resource: its cultural events. Rauma's community appears deeply committed in its promotion: during the year, many of cultural events are organized by different association and subjects, especially in summer. These activities mostly consist in fairs, festivals and expositions that not only attract people to the town, but also allow them to get in contact with local culture, intangible heritage and to discover the most private side of the World heritage site (Figure 12).

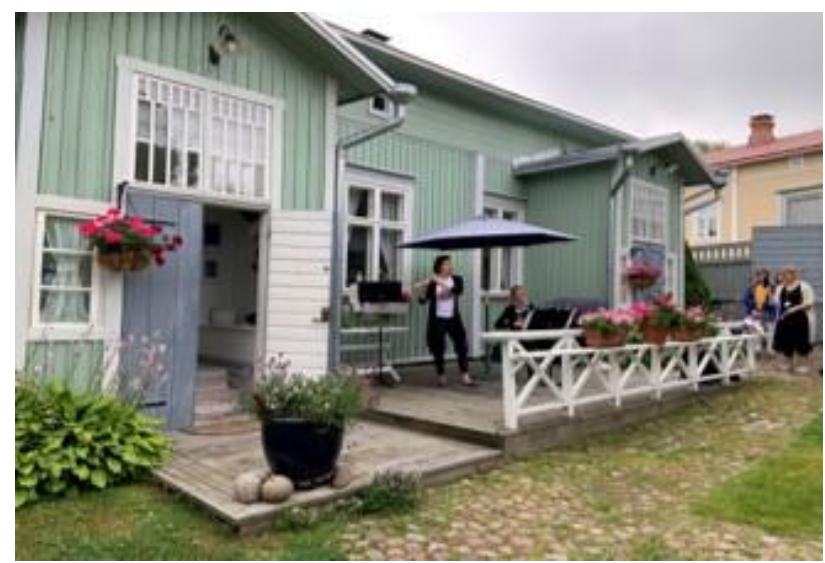

Figure 12. Picture from Rauma Festivo, a festival that took place between 6th and 10th of August 2019. One of the events consisted in short itinerant classical music concerts, that went on during the day inside private yards of Old Rauma. (photograph by the author, 2019)

Also, many of educational activities take place in Old Rauma, especially at Tammela, involving kids, teenagers and university students in different projects that contribute to get them used to heritage since childhood, creating and important bound with it.

Tammela Renovation Centre is a municipal institution that was founded in 1995 (Ahoniemi et al, 1999); it is housed by a traditional old building, located in the southern part of the protected area. The original structure dates to the 19th century and it was built as a residency for several owners. The construction was expanded at the end of the same century and it was later turned into a music school between 1976 and 1977.

After its rehabilitation, Tammela was brought back the shape of 1903 building (Ahoniemi et al, 1999) and nowadays it is composed by the main edifice, one wooden storage, a bricks sauna structure that dates back to 40 s of 20th century and a large workshop. The storage is stocked with old windows, doors and old traditional materials that can be bought by costumers, while the workshop is equipped with all the facilities for wooden works. The sauna and the main house can be freely visited during summertime, when the Centre stays open all day long. In the inside constructive, historical and folkloristics information are displayed, not only by panels and diagrams but also by directly "exposing" the house itself through archaeological windows that show walls structure and many of other different details.

Besides, Tammela is also the place where many of cultural events about heritage take place: local, national and international conferences, traditional repair fairs, scholars and academic activities and international events. 


\section{CONCLUSIONS}

\subsection{Limits of the research}

The research was structured to provide overall preliminary information: its results can be convenient to present Old Rauma through the general description of its history, urbanism, architecture, conservation and culture. It is not possible to consider it like an exhaustive and complete analysis of each ones of the investigated fields. For this aim, it would be recommendable to adopt a more specific methodology and to temporally extend the analysis. First, it would be necessary to repeat the various studies in order to verify all the hypotheses; it would be extremely significant to explore more buildings and also to confront analogous situations (such as Pori old town preserved area, Porvoo ${ }^{8}$, etc.) to find similarities and differences. Those results would make possible to better define the Nordic traditional wooden urbanism and architecture.

Furthermore, it would be necessary to accurately carry out measured analyses, using precise tools such as laser apparatus that could guarantee a correct definition of metrical and dimensional aspects, which can be used to propose accurate and adequate intervention operations and strategies. The materials and degradation studies should be corroborated with chemicals and technical tests, which would return optimal simulations and responses for better understand materials physic and molecular structure and behaviours. These verified notions and information could finally be employed to accurately describe the conservation state, by detecting degradation phenomena causes and modalities. Finally, it would be recommendable to also include, in the investigation team, an expert in local language who can result extremely useful to remove the comprehension limits connected with linguistic matters. It could be convenient especially for widening the bibliographical range, in this case almost totally limited to English texts.

\subsection{Final considerations}

Old Rauma case revealed various cues of reflection and peculiar actions and practices that could be studied with the intent to export them to other towns and countries. Its state of conservation and its inhabitants' commitment in care showed that education of users and their affiliation to culture and architecture are crucial for Heritage preservation and diffusion. This fact results even more actual when related to inhabited Heritage such as Old Rauma's, where owners and tenants' actions are vital for the building.

In fact, people appear to have a major propensity on taking care of an ancient architecture when they have feelings of belonging with it; in this panorama, the role of Tammela and the entities that work together with the Centre is very important and crucial. Tammela not only encourages users towards good practices, by directly supporting them in building and renovating processes, but it also organizes cultural activities that shape the conscience and the sensibility of citizens about traditional architecture, getting them used to their own heritage since childhood. This way people develop an affiliation to it and learn the ability of knowing and understanding it. They recognize its limitations and fragilities but also its potentialities and it becomes easier, for them, to accept it and to take care of it, by understanding its deep value an considering it a part of their history and identity.

\footnotetext{
Porvoo is another medieval Finnish Old Town, located in Southern Finland. Due to its good state of preservation, it was Old Rauma "rival" in the World Heritage Site declaration process. At the end, only Rauma received it.
}

Old Rauma case showed that although it is important to have good specialists it is also necessary and crucial to build and train not-professional public, in order to conserve Heritage in a safe and not completely "musealised" way. And education is a very powerful and effective tool to this cause.

\section{ACKNOWLEDGEMENTS}

The previous text presented the results of some months of research on Old Rauma urbanism, architecture, conservation and valorisation carried out by the author for her Master's Degree in Preservation of Architectural Heritage final dissertation. The work was directed by Camilla Mileto, Fernando López VegasManzanares and Lidia García Soriano, taking part in the research project 3D Past - "Living and virtual visiting world heritage" [Grant Agreement Ref No570729-CREA-1-2016-1-PT-CULTCOOP1], which was co-funded by the European Union, under the programme Creative Europe (2016-2020); the stay at Tammela Renovation Centre as trainee was possible thank to an Erasmus+ Traineeship Fellowship granted to the author by the Polytechnical University of Valencia.

I would like to show my gratitude to all the figures who helped me during this research, through their support, knowledge and efforts. First, I would like to express my gratitude to Tammela Centre and RaumArs association. I especially thank Jussi Telaranta, World Heritage Coordinator at Tammela, and Hannele Kolsio, RaumArs executive director, for welcoming me into the Centre and the Residency and for enthusiastically supporting my research project through the events they involved me in, the visits, the share of their knowledge and the constant help. I am also grateful to Toivo Centre and its intendant Tuulikki Kiilo for the precious information she provided and for her kind support. Finally, I would like to thank the City of Rauma and the whole town community for the interest showed and the contribution to my research activities.

\section{REFERENCES}

Ahoniemi, A., Markela, N., Saarinen, K., 1999. A guide to alteration and renovation of a historical timber building using traditional methods and materials, https://www.vanharauma.fi/wpcontent/uploads/sites/16/2018/08/17.8-A5-Tammelaopas-2016in-english.pdf (28 january 2018)

Dumitrescu, A., 2016. The Management of Change in Finland's Wooden Historic Urban Landscapes: Old Rauma. PhD Thesis, Tampere University of Technology. Publication, vol. 1357, Tampere University of Technology. https://trepo.tuni.fi//handle/10024/114953 (30 January 2020)

Jämsä, E., 2012. Rauma, Kirjakaari, Jyväskylä

Koivula, J., Nurmi-NIelsen, A., Saarinen, K., Tyllilä, I., 1992, Vanha Rauma. Old Rauma, Rauman Museum, Rauma

Raitio, H., Tammi, M., 2018. Vahna Rauma. Sailyttamisesta ja tekemisesta, Rauman kaupunki, Rauma

Salo, A., Sundelin, R., 2015. Vanha Rauma-Old Rauma, Kustantaja Lansituuli, Rauma

Saarinen, K., 2013, Viivan Pakottaminen in Telaranta, J., Rauman Kaupunki, 2013, Viivat Kertovat. Mittaurspiirustusleirit Vanhassa Raumassa, Rauman kaupunki, Rauma. 